\title{
HEPATOPROTECTIVE AND ANTIDYSLIPIDEMIC ACTIVITIES OF METHANOLIC EXTRACT OF GARCINIA KOLA LEAVES IN STREPTOZOTOCIN-INDUCED DIABETIC RATS
}

\author{
Faith Ajiebabhio Ogbole \\ Department of Chemical Sciences \\ University of Africa, Toru - Orua, \\ Bayelsa State, Nigeria
}

Olanrewaju Sam Olayeriju

Department of Biochemistry

Federal University of Technology Akure

Ondo State, Nigeria

\author{
Olamide Olajusi Crown \\ Department of Biochemistry \\ Federal University of Technology Akure, \\ Ondo State, Nigeria \\ Mary Tolu Olaleye \\ Department of Biochemistry \\ Federal University of Technology Akure \\ Ondo State, Nigeria
}

\author{
Afolabi Akintunde Akindahunsi \\ Department of Biochemistry \\ Federal University of Technology Akure \\ Ondo State, Nigeria
}

\begin{abstract}
Garcinia kola is called a wonder plant in forklore medicine because every part of the plant has therapeutic value. This study aimed at investigating the hepatoprotective and antidyslipidemic activities of methanolic extract of Garcinia kola leaves in streptozotocin-induced diabetic rats. The animals were divided into seven groups of six animal each: vehicle; 100 $\mathrm{mg} / \mathrm{kg}$ Garcinia kola leaf extract; $200 \mathrm{mg} / \mathrm{kg}$ Garcinia kola leaf extract; untreated diabetic group; treated diabetic group administered $100 \mathrm{mg} / \mathrm{kg}$ Garcinia kola leaf extract; treated diabetic group administered $200 \mathrm{mg} / \mathrm{kg}$ Garcinia kola leaf extract; and treated diabetic group administered glibenclaimide $0.5 \mathrm{mg} / \mathrm{kg}$. Results for serum lipid profile showed a significant decrease in triglyceride, total cholesterol, very low density lipoprotein-cholesterol and low density lipoprotein-cholesterol as well as a significant increase in high density lipoprotein cholesterol in the extract treated diabetic groups compared to the untreated diabetic group. Similarly, a significant increase in the antioxidant activity of hepatic catalase as well as a significant decrease in lipid peroxidation were also observed in the extract treated diabetic rats compared to the untreated rats. Histopathological examination of the hepatic tissues of the extract treated diabetic rats showed active regeneration of the hepatocytes, well preserved
\end{abstract}

architecture and the absence of lesions and necrosis compared to the untreated group which showed severe necrosis, inflammation and degeneration of hepatocytes. The extract showed better improvement in treating diabetes-induced dyslipidemia and liver damage compared with the standard antidiabetic drug, glibenclaimide. This study suggests that Garcinia kola leaves might be an effective phytotherapy for treating diabetes-induced complications.

Keywords - Antidyslipidemic, Antioxidant, Diabetes mellitus, Garcinia kola leaves, Hepatoprotective

\section{INTRODUCTION}

Diabetes mellitus is a complex metabolic disorder that is characterized by hyperglycemia. Among the complications that commonly accompany diabetes are dyslipidemia [1] and liver damage [2]. One of the known mechanisms by which diabetes mellitus induces liver damage is by causing an abnormal increase in oxidative stress which is simultaneously accompanied by an inflammatory response to the oxidative stress. Previous studies have reported that liver diseases occur at higher frequency in diabetic patients [2]. Also, dyslipidemia which is characterized by an abnormal increase in low-density 


\section{International Journal of Engineering Applied Sciences and Technology, 2019 \\ Vol. 4, Issue 4, ISSN No. 2455-2143, Pages 1-5 \\ Published Online August 2019 in IJEAST (http://www.ijeast.com)}

lipoprotein cholesterol and an abnormal decrease in high density lipoprotein cholesterol are common features in patients with diabetes. Later complications of diabetes-induced dyslipidemia and liver damage are cardiovascular diseases such as atherosclerosis and myocardial infarction, stroke and hypertension [3]. Aside, from the fact that most drugs used in the management of diabetes do not treat these complications, antidiabetes medications also pose serious side effects. These concerns have necessitated research on medicinal plants that could both treat diabetes as well as its complications [4].

Extracts from medicinal plants have been used to treat and manage a number of diseases over the years. One of such medicinal plants is Garcinia kola commonly referred to as bitter kola. Garcina kola is popularly called a wonder plant in folklore medicine because every part of the plant has acclaimed therapeutic value. The seeds of Garcinia kola ( $G$. kola) are used in the treatment of bronchitis, tumor, cough and diabetes, while the root and bark are taken as a tonic for sexual dysfunction in men and to ease child birth. Although a previous study carried out on the leaves of $G$. kola confirmed that $G$. kola leaves possess antidiabetic and antioxidant activities due to the presence of phytochemicals in the leaves [6], however, in literature, limited scientific study exist to validate the effect of $G$. kola leaves on diabetes-induced dyslipidemia and liver damage. This research gap is what this study sought to fill.

\section{MATERIALS AND METHODS}

\section{A. Chemicals and drug -}

Assay Kits for high density lipoprotein-cholesterol, triglyceride, total cholesterol and total protein, as well as streptozotocin (STZ) and glibenclamide were purchased from Randox Laboratories Limited, 55 Diamond Road, Crumlin, County Antrim, United Kingdom. All other reagents used in this study were of analytical grade. Solutions and buffers were prepared using glass distilled water.

\section{B. Plant Material and extraction -}

Young and fresh leaves of Garcinia kola were collected from a farm in Akure, Nigeria and were identified by a taxonomist at the Herbarium in Botany Department, Obafemi Awolowo University, Nigeria. Extraction was carried out according to a previously described method [7]. Briefly, the air dried Garcinia kola leaves were pulverized and exactly $500 \mathrm{~g}$ of the powdered leaves was macerated into $80 \%$ methanol $(6.5 \mathrm{~L})$. The clear filtrate (methanolic crude extract of Garcinia kola leaves) was evaporated to dryness and stored in an air tight container.

\section{Animals and experimental design -}

Albino Wistar rats purchased from the central animal house, University of Ibadan were acclimatized to laboratory conditions (12 hours light / 12 hours dark cycle, room temperature $25-28^{\circ} \mathrm{C}$ and relative humidity $70-80 \%$ ) for two weeks. The rats had free access to standard commercial rat chow pellets as well as tap water and they were handled in accordance with the international guide for the care and use of laboratory animals. The animals were divided into seven groups $(n=6)$, according to a previously described method [7]: Vehicle (administered distilled water); GKLE (100 mg/kg b. wt); GKLE (200 mg/kg b. wt); diabetic rats (no treatment); GKLE treated diabetic rats (GKLE $100 \mathrm{mg} / \mathrm{kg}$ b. wt.); GKLE treated diabetic rats (GKLE $200 \mathrm{mg} / \mathrm{kg}$ b. wt.); Glibenclaimide treated diabetic rats (Glibenclaimide $0.5 \mathrm{mg} / \mathrm{kg}$ b. wt.).

\section{$D$. Diabetes induction and glucose estimation -}

Diabetes induction was carried out according to a previously described method [6]. Briefly, freshly prepared solution of STZ (65 mg/kg b. wt) in ice-cold $0.1 \mathrm{M}$ citrate buffer, $\mathrm{pH} 4.5$, was administered intraperitoneally as a single dose to overnight fasted Wistar rats after baseline glucose estimation. Animals with blood glucose concentration $\geq 250 \mathrm{mg} / \mathrm{dl}$ seventy-two hours after diabetes induction were considered diabetic. Fasting blood glucose concentration was evaluated using AccuChek compact glucometer (Roche, Madrid, Spain).

\section{E.. Sacrifice, histopathological examination, serum and liver tissue preparation -}

Following the protocol of a previously described method [7], the animals were sacrificed by cervical dislocation at the end of the experimental period. Blood was drawn from the heart and collected into plain serum bottles. The liver of each rat was excised, washed in $1.15 \% \mathrm{KCl}$ solution, blotted dry and weighed. A portion of the liver of each rat was fixed in $10 \%$ formalin for histopathological analysis, while the remaining portion was homogenized in saline solution $(0.9 \%)$ for biochemical assay.

\section{F. Biochemical assay -}

The activity of hepatic catalase and the level of thiobarbituric acid reactive substances (TBARS) in the liver were estimated using previously described methods [8,9]. The concentrations of low density lipoprotein-cholesterol (LDL-C), high density lipoprotein-cholesterol (HDL-C), very low density lipoprotein-cholesterol (VLDL-C), triglyceride, total cholesterol and total protein were analyzed using the manufacture's protocol of commercially available Randox assay kits.

\section{G. Statistical analysis assay -}

Values were expressed as mean \pm SEM of five animals. One Way Analysis of Variance (ANOVA) followed by Duncan Multiple Range Test was used to estimate differences between multiple groups where appropriate. The significance level was set at $p<0.05$. 


\section{International Journal of Engineering Applied Sciences and Technology, 2019 Vol. 4, Issue 4, ISSN No. 2455-2143, Pages 1-5 \\ Published Online August 2019 in IJEAST (http://www.ijeast.com)}

\section{RESULTS}

A. Increase in the antioxidant activiy of hepatic catalase Table 1 shows that there was a significant increase in the activity of hepatic catalase in the Garcinia kola leaf extract (GKLE) treated diabetic groups compared to the untreated diabetic group.

Table - 1. Effect of GKLE on the antioxidant activity of hepatic catalase in STZ-induced diabetic rats

\begin{tabular}{|l|l|}
\hline \multicolumn{1}{|c|}{ Groups } & \multicolumn{1}{c|}{$\begin{array}{c}\text { Hepatic Catalase activity } \\
(\mathrm{mU} / \mathrm{mg} \text { protein })\end{array}$} \\
\hline I & $1.28 \pm 0.09^{\mathrm{a}}$ \\
\hline II & $7.80 \pm 0.10^{\mathrm{b}}$ \\
\hline III & $10.18 \pm 0.18^{\mathrm{c}}$ \\
\hline IV & $0.12 \pm 0.03^{\mathrm{d}}$ \\
\hline V & $6.90 \pm 0.12^{\mathrm{e}}$ \\
\hline VI & $7.70 \pm 0.05^{\mathrm{b}}$ \\
\hline VII & $1.3 \pm 0.58^{\mathrm{f}}$ \\
\hline
\end{tabular}

Result is presented as mean \pm SEM of five independent experiments, each performed in triplicates. Values with different superscripts are significantly different $(p<0.05)$. Group I: Vehicle (distilled water); Group II: GKLE (100 $\mathrm{mg} / \mathrm{kg} \mathrm{b}$. wt); Group III: GKLE (200 mg/kg b. wt); Group IV: untreated diabetic group; Group V: GKLE (100 mg/kg b. wt.) treated diabetic group; Group VI: GKLE $(200 \mathrm{mg} / \mathrm{kg}$ b. wt.) treated diabetic group; Group VII: Glibenclaimide $(0.5 \mathrm{mg} / \mathrm{kg})$ treated diabetic group. GKLE $=$ Garcinia kola methanolic leaf extract

\section{$B$. Decrease in the level of lipid peroxidation -}

The lipid peroxidation lowering effect of GKLE in STZinduced diabetic rats is presented in Figure 1. A significant decrease in lipid peroxidation measured as the level of thiobarbituric acid reactive substances (TBARS) was observed in the extract treated diabetic groups compared to the untreated group at all doses of the extract used.

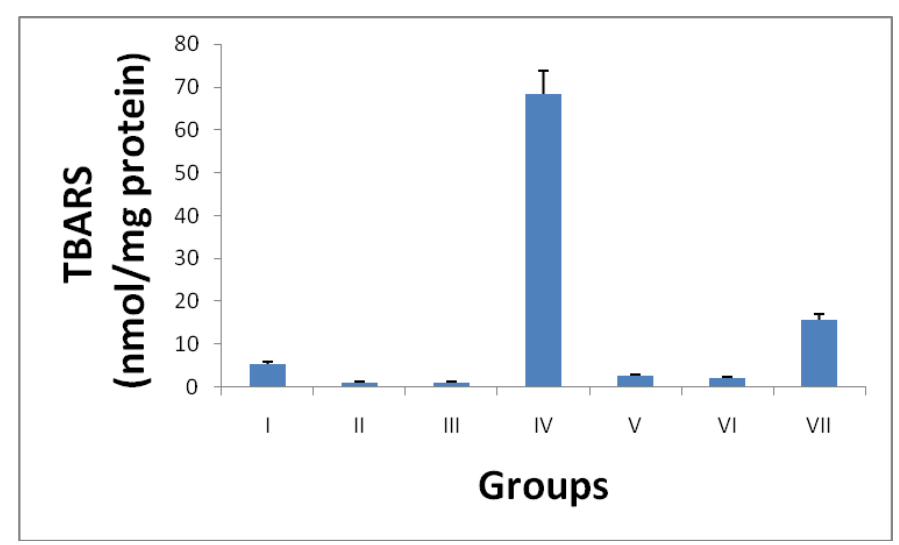

Fig. 1 Effect of GKLE on hepatic TBARS in STZinduced diabetic rats

Result is presented as mean \pm SEM of five independent experiments, each performed in triplicates. Group I: Vehicle (distilled water); Group II: GKLE (100 mg/kg b. wt); Group III: GKLE (200 mg/kg b. wt.); Group IV: untreated diabetic group; Group V: GKLE (100 mg/kg b. wt.) treated diabetic group;
Group VI: GKLE (200 mg/kg b. wt.) treated diabetic group; Group VII: Glibenclaimide $(0.5 \mathrm{mg} / \mathrm{kg})$ treated diabetic group. GKLE = Garcinia kola methanolic leaf extract.

\section{Antidyslipidemic effect of GKLE -}

Table 2 shows the antidyslipidemic effect of GKLE in STZinduced diabetic rats. A significant increase in the level of HDL-cholesterol and a significant decrease in the level of LDL-cholesterol, VLDL-cholesterol, triglyceride and total cholesterol were observed in the extract treated diabetic group compared to the untreated diabetic group.

Table 2: Effect of GKLE on serum lipid profile in STZ-induced Diabetic Rats

\begin{tabular}{|c|c|c|c|c|c|}
\hline & \multicolumn{5}{|c|}{ Serum lipid profile (mg/dl) } \\
\hline GP & Trig & TC & HDL-C & LDL-C & VLDL-C \\
\hline I & 98.00 & 95.00 & 60.00 & 15.4 & 19.60 \\
& $\pm 0.84^{\mathrm{b}}$ & $\pm 0.01^{\mathrm{a}}$ & $\pm 0.01^{\mathrm{a}}$ & $\pm 0.84^{\mathrm{b}}$ & $\pm 0.84^{\mathrm{g}}$ \\
\hline II & 60.00 & 76.20 & 62.60 & 1.60 & 12.00 \\
& $\pm 0.01^{\mathrm{e}}$ & $\pm 0.20^{\mathrm{f}}$ & $\pm 0.40^{\mathrm{g}}$ & $\pm 0.84^{\mathrm{e}}$ & $\pm 0.84^{\mathrm{b}}$ \\
\hline III & 40.64 & 74.04 & 65.00 & 0.912 & 8.13 \\
& $\pm 0.20^{\mathrm{h}}$ & $\pm 0.01^{\mathrm{d}}$ & $\pm 1.58^{\mathrm{h}}$ & $\pm 0.01^{\mathrm{c}}$ & $\pm 0.20^{\mathrm{d}}$ \\
\hline IV & 180.60 & 150.00 & 4.66 & 109.34 & 36.00 \\
& $\pm 26.2^{\mathrm{a}}$ & $\pm 0.01^{\mathrm{b}}$ & $\pm 0.29^{\mathrm{b}}$ & $\pm 0.84^{\mathrm{g}}$ & $\pm 0.84^{\mathrm{f}}$ \\
\hline V & 60.00 & 79.00 & 60.40 & 6.20 & 12.40 \\
& $\pm 0.63^{\mathrm{f}}$ & $\pm 0.24^{\mathrm{g}}$ & $\pm 0.25^{\mathrm{a}}$ & $\pm 0.84^{\mathrm{f}}$ & $\pm 0.84^{\mathrm{h}}$ \\
\hline VI & 53.00 & 77.00 & 62.20 & 4.2 & 10.60 \\
& $\pm 0.84^{\mathrm{g}}$ & $\pm 0.40^{\mathrm{c}}$ & $\pm 0.20^{\mathrm{f}}$ & $\pm 0.84^{\mathrm{d}}$ & $\pm 0.84^{\mathrm{h}}$ \\
\hline VII & 108.20 & 98.24 & 56.60 & $20.00^{\mathrm{y}}$ & 21.64 \\
& $\pm 5.90^{\mathrm{d}}$ & $\pm 0.03^{\mathrm{e}}$ & $\pm 0.68^{\mathrm{d}}$ & $\pm 0.84^{\mathrm{a}}$ & $\pm 0.84^{\mathrm{c}}$ \\
\hline
\end{tabular}

Result is presented as mean \pm SEM of five independent experiments, each performed in triplicates. Values with different superscripts in a column are significantly different $(p<0.05)$. Group I: Vehicle (distilled water); Group II: GKLE (100 mg/kg b. wt); Group III: GKLE (200 mg/kg b. wt); Group IV: untreated diabetic group; Group V: GKLE (100 mg/kg b. wt.) treated diabetic group; Group VI: GKLE $(200 \mathrm{mg} / \mathrm{kg}$ b. wt.) treated diabetic group; Group VII: Glibenclaimide $(0.5 \mathrm{mg} / \mathrm{kg})$ treated diabetic group. GKLE = Garcinia kola methanolic leaf extract.GKLE = Garcinia kola methanolicleaf extract, $\mathrm{TC}=$ Total cholesterol, Trig $=$ triglyceride, HDL-C $=$ high density lipoprotein cholesterol, LDL-C = low density lipoprotein cholesterol, VLDL-C = very low density lipoprotein cholesterol.

\section{Effect of GKLE on liver damage}

Histopathological examination of the hepatocytes of extract treated diabetic rats showed active regeneration and absence of lesions (Figure V-VI) compared to the hepatocytes of untreated diabetic rats (Figure IV) in which there was architectural degeneration as well as necrosis. 
International Journal of Engineering Applied Sciences and Technology, 2019

Vol. 4, Issue 4, ISSN No. 2455-2143, Pages 1-5

Published Online August 2019 in IJEAST (http://www.ijeast.com)
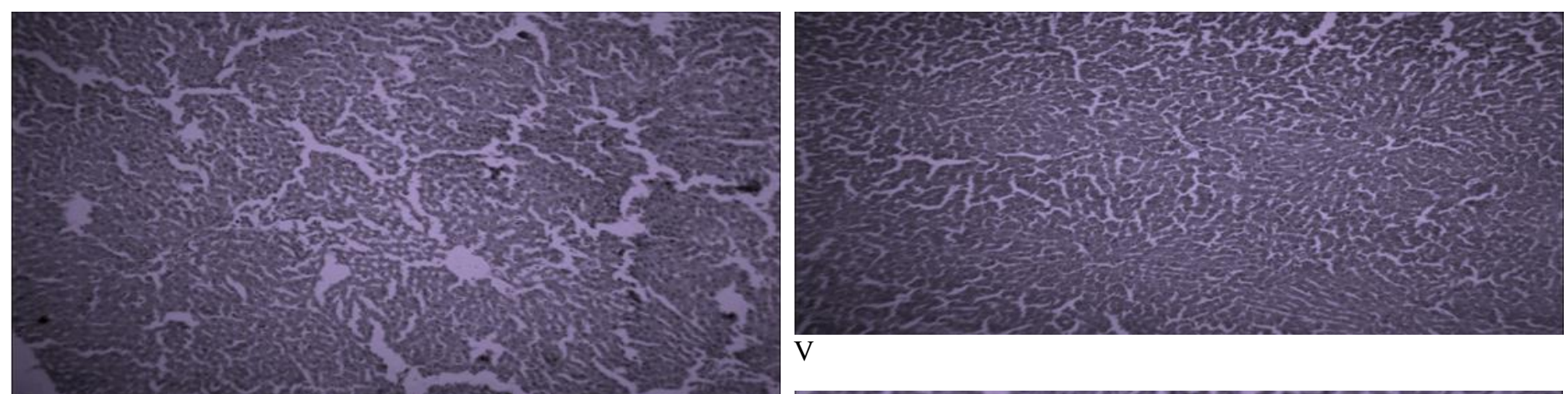

$\mathrm{V}$

\section{I}
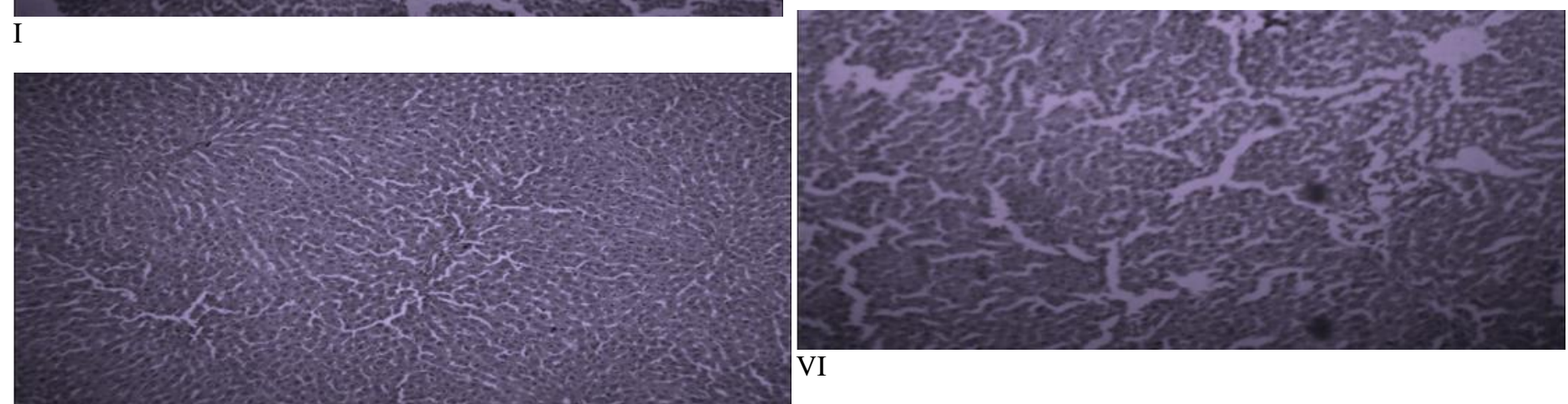

11

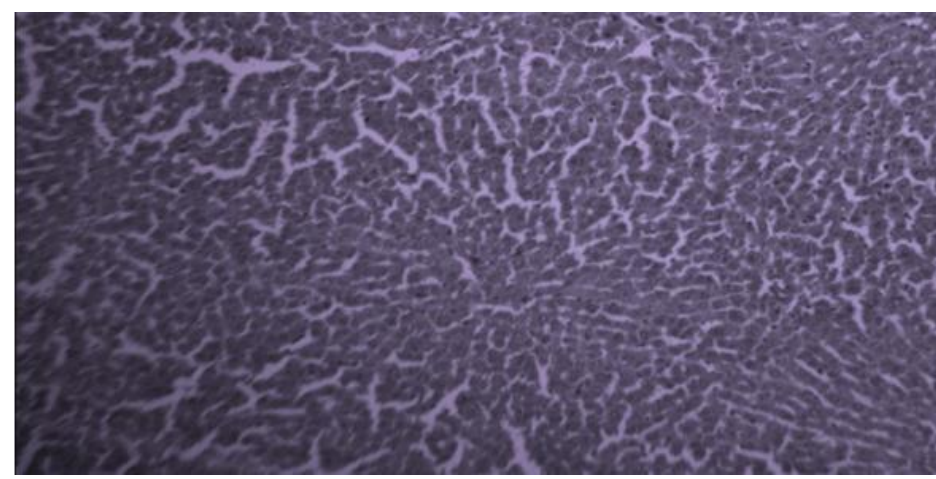

III

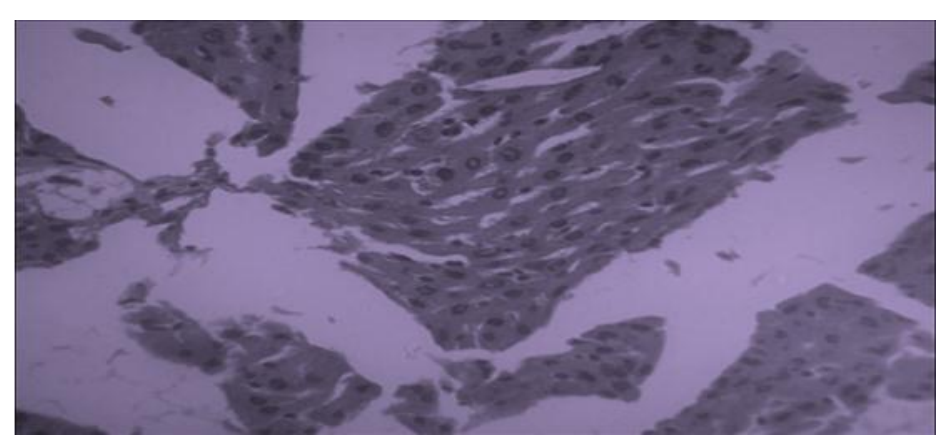

IV

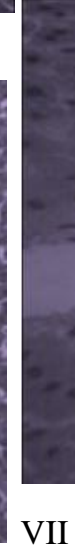

VII

Figure 2: Histopathological examination of the hepatic tissues of experimental rats. I: Vehicle (distilled water); II: GKLE $(100 \mathrm{mg} / \mathrm{kg}$ b. wt); III: GKLE (200 mg/kg b. wt); IV: untreated diabetic group; V: GKLE $(100 \mathrm{mg} / \mathrm{kg}$ b. wt.) treated diabetic group; VI: GKLE $(200 \mathrm{mg} / \mathrm{kg}$ b. wt.) treated diabetic group; VII: Glibenclaimide $(0.5 \mathrm{mg} / \mathrm{kg})$ treated diabetic group. GKLE = Garcinia kola methanolic leaf extract.

\section{DISCUSSION}

The result of the lipid profile assay of this present study is in agreement with the results of previous studies in which a significant decrease in total cholesterol, triglyceride, LDL-C and VLDL-C as well as a significant increase in HDL-C were observed after the administration of plant extract to STZinduced diabetic mice $[10,11,12]$. Also previous studies [13, 14] corroborates the result of this present study on the restoration of damaged hepatocytes architecture and the disappearance of degeneration, lesion and necrosis in the liver 


\section{International Journal of Engineering Applied Sciences and Technology, 2019 \\ Vol. 4, Issue 4, ISSN No. 2455-2143, Pages 1-5 \\ Published Online August 2019 in IJEAST (http://www.ijeast.com)}

after treating diabetic rats with plant extracts. Furthermore, the increase in hepatic catalase activity and the decrease in hepatic lipid peroxidation in the Garcinia kola leaf extract treated diabetic group is also in agreement with the result of a similar previous study [5]. The result of this present study shows that the leaves of Garcinia kola does not only treat diabetes but also treats the complications of diabetes. One possible explanation for the hepatoprotective and dyslipidemic effects of the methanolic extract of Garcinia kola leaves might be the ability of the extract to boost the antioxidant capacity of the cells of diabetic rats

\section{CONCLUSION}

The result of this study suggests that Garcinia kola leaves exhibit hepatoprotective and antidyslipidemic effects in streptozotocin-induced diabetic rats. This may have implications for drug discovery. However further studies need to be carried out to ascertain whether these observed results could be replicated in humans.

\section{REFERENCES}

[1] Goldberg R.I (2001). Diabetic dyslipidemia: Causes and Consequences, Journal of Clinical Endocrinology and Metabolism, 86(3): 965-971.

[2] Mohamed J., Nafizah, A.H.N., Zariyantey A.H. and Budin, S.B. (2016). Mechanisms of Diabetes-Induced Liver Damage: The role of oxidative stress and inflammation. Sultan Qaboos University medical journal, 16(3).

[3] Narindrarangkura P. Bosl W., Rangsin R., and Hatthachote, P. (2019). Prevalence of dyslipidemia associated with complications in diabetic patients: a nationwide study in Thailand. Journal of Lipids in health and disease. 18(1): 1034-1043.

[4] Khaled H., Zeinab A., El-Dahshan N. (2015). Patterns and obstacles to oral antidiabetic medications adherence among type 2 diabetics in Ismailia, Egypt: a cross section study. The Pan African Medical Journal, 20: 177 - 182.

[5] Ekene E. N., and Erhirhie E. O. (2014). Garcinia kola: A review of its ethnomedicinal, chemical and pharmacological properties. International Journal of Current Research and Review, 6(11): $1-7$.

[6] Ogbole F.A., Crown O.O, Olayeriju O.S., Olaleye M.T., Akindahunsi A.A. (2019). Antidiabetic effect of methanolic extract of Garcinia kola leaves on streptozotocin-induced diabetic rats. Global Scientific Journal, 7 (4): 634 - 641.

[7] Panda S.P., Haldar P.K., Bera S., Adhikary S., and Kandar C.C. (2010). Antidiabetic and antioxidant activity of Swieteniamahagoni in streptozotocin-induced diabetic rats. Journal of Pharmaceutical Biology, 48(9): 974-979.

[8] Singh J., Bagla A., and Pahal V. (2010). Hepatoprotective activity of herbal extracts in carbon tetrachloride intoxicated albino rats by measuring anti-oxidant enzymes. International Journal of Pharmaceutical Technology Research, 2(3): 2112-2115.

[9] Ohkawa H. Ohishi N. and Yagi K. (1979). Assay for lipid peroxides in animal tissues by thiobarbituric acid reaction. Analytical biochemistry, 95(2): 351-358.

[10] Atef M.A., and Talal A.Z. (2010). Influences of crude extract of tea leaves, Camellia sinensis, on streptozotocininduced diabetic male albino mice. Saudi Arabia Journal of Biological Science, 17(4): 295-301.

[11] Adaramoye O.A., Akintayo O., Achem J., and Fafunso M.A. (2008). Lipid-lowering effects of methanolic extract of Vernonia amygdalina leaves in rats fed on high cholesterol diet. Journal of Vascular Health and Risk Management, 4(1), 235-241.

[12] Fernandes A.A.H., Ethel L.B.N, Ary, J.F., Cristiano M.G. (2009). Effect of naringerin on biochemical parameters in the streptozotocin-induced diabetic rats. Brazillian Archives of Biology and Technology, 52(1).

[13] Abeer M.E., Ola A.E., Abdulqawi K., and Wahba, O. (2013). The protective role of a flavonoid "morin" on the liver of streptozotocin-induced diabetic rats. Medical Journal of Cairo University, 81: 1025-1034.

[14] Adeyemi D.O., Ukwenya V.O., Obuotor E.M., Adewole S.O. (2014). Anti-hepatotoxic activities of Hibiscus sabdariffa L. in animal model of streptozotocin diabetesinduced liver damage," BMC Complementary and Alternative Medicine, 14(277): 1-11.

[15] Mishra C., Khalid M.A., Fatima N., Singh B., Tripathi D., Waseem M., and Mahdi A.A. (2019). Effects of citral on oxidative stress and hepatic key enzymes of glucose metabolism in streptozotocin/high-fat-diet induced diabetic dyslipidemic rats. Iranian Journal of Basic Medical Sciences, 22(1): 49-57. 